\title{
Analisis Kenerja Maximum Power Point Tracker (MPPT) Pada Sistem Photovoltaic Standalone Berbasis Algoritme Perturb And Observe ( $\mathrm{P} \& \mathrm{O})$
}

\author{
Agim Tetuko \\ Program Studi teknk Elektro, \\ Fakultas teknik \\ Universitas Negeri Semarang \\ Kampus Sekaran, Gunungpati, \\ Semarang, Indonesia \\ agim_tetuko16@students.unnes.ac.id
}

\author{
Djuniadi \\ Program Studi teknk Elektro, \\ Fakultas teknik \\ Universitas Negeri Semarang \\ Kampus Sekaran, Gunungpati, \\ Semarang, Indonesia \\ djuniadi@mail.unnes.ac.id
}

\author{
Esa Apriaskar \\ Program Studi teknk Elektro, \\ Fakultas teknik \\ Universitas Negeri Semarang \\ Kampus Sekaran, Gunungpati, \\ Semarang, Indonesia \\ esa.apriaskar@mail.unnes.ac.id
}

\begin{abstract}
A solar power plant or photovoltaic (PV) is a generator that converts energy from light into pollution-free electrical energy. However, changes in the intensity of solar radiation and ambeint temperature Photovoltaic (PV) which are not linear are the main problems of PV systems in efficient energy conversion that occurs. Control using the Maximum Power Point Tracker (MPPT) method based on the Perturb and Observe (P\&O) algorithm which is applied to overcome these problems. Maximum Power Point Tracker (MPPT) itself is a technique for tracking the maximum output power point of the PV system. MPPT will change the working point so that the converter will force the work of the solar panels according to their ability to always reach the maximum power point. MPPT is not a mechanical system that makes the solar panel system move according to the direction of the sun's intensity, but an electronic system that works to optimize the power output from the solar panel. Meanwhile, Algorithm (P\&O) works by detecting and disturbing the $P V$ voltage periodically by varying its duty cycle, as well as observing the $P V$ power to be able to increase and decrease the PV voltage in the next 3 cycles. This paper presents an analysis of the MPPT P\&O performance with a standalone system implemented in the campus area. In this study, the applied PV system was able to produce a maximum power of 1626.087 Watts under optimal irradiation conditions and temperature. As well as testing the PV system under radiation and temperature conditions in the location study, namely FT UNNES. The maximum power of the PV system is 227.585 Watt.
\end{abstract}

Keywords-Photovoltaic (PV), MPPT, Perturb and Observe $(\mathrm{P} \& O)$.

\section{PENDAHULUAN}

Permintaan energi global terus meningkat beriringan dengan masalah lingkungan yang terjadi karena pembangkit energi konvensional berbahan bakar fosil, melahirkan kesadaran masyarakat dunia untuk lebih mendayagunakan energi terbarukan seperti energi matahari, energi angin, dan bio-energi [1]. Asia Tenggara memiliki potensi energi terbarukan yang sangat tinggi untuk dimanfaatkan dimana sebagian besar negaranya merupakan kawasan tropis. Sepuluh negara ASEAN telah membidik total bauran energi terbarukan sebesar 23\% pada tahun 2025 [2]. Indonesia juga ikut andil dalam mengupayakan pendayagunaan sumber energi terbarukan dalam rangka bagian untuk menjaga kemandirian dan ketahanan energi nasional, berdasarkan PP No. 79 Tahun 2014 tentang Kebijakan Energi Nasional, yaitu target energi baru terbarukan pada tahun 2025 dan 2050 paling sedikit $23 \%$ dan $31 \%$ [3]. Potensi energi baru terbarukan yang terbesar di Indonesia adalah Photovoltaik (PV) sebesar 532,6 GW yang berkisar antara 4,0 - 6,9 kWh / $\mathrm{m} 2$ dan rata-rata 4,8 kWh / m2 [4], [5]. Energi cahaya matahari yang tidak akan habis menjadikan alasan pembangunan Pembangkit listrik tenaga surya semakin meningkat. Daya yang di produksi dan di simpan oleh Photovoltaic (PV) dipengaruhi oleh intensitas radiasi cahaya matahari dan temperature pada permukaan PV. Namun perubahan kedua faktor ini yang tak linear menjadikan sebuah masalah utama dalam sistem PV sehingga sulit mengkonversikan energi listrik secara efisien dan maksimal [6]. Oleh karena itu, diperlukan metode kontrol daya yang mampu memastika daya output dari panel surya selalu dalam keadaan maksimal.

Telah dikembangan suatu sistem yang disebut Maximum Power Point Tracker (MPPT). MPPT bekerja dengan cara melacak daya maksimum dari panel PV dan mengirimkannya ke pengontrol pengisian baterai [7]. Namun pengontrolan MPPT tidak akan berjalan dengan maksimal tanpa adanya sistem cerdas yang mampu menangani kasus pengoptimalan MPPT. Terdapat beberapa algoritme MPPT yang telah dikembangkan oleh beberapa peneliti sebelumnya, seperti Perturb and Observe (P\&O), Artificial Neural Network method, Fuzzy Logic method, dll. Algoritme tersebut berbeda sesuai dengan aspek nya masing masing seperti kesederhanaan, kecepatan, biaya, efektifitas, dan lain sebagainya [8]. Perturb and Observe (P\&O) adalah salah satu algoritme kontrol MPPT yang bekerja dengan mengatur tegangan referensi larik dan ukuran langkah tegangan untuk mencapai titik daya maksimum. Algoritme P\&O memungkinkan kinerja MPPT yang lebih baik dan mampu menangani variasi daya dan tegangan pada PV sistem [1]. Penelitian ini dilakukan guna merancang sebuah sistem pembangkit photovoltaic (PV) sebagai 


\section{Analisis Kenerja Maximum Power Point Tracker (MPPT) Pada Sistem Photovoltaic Standalone Berbasis Algoritme Perturb And Observe (P\&O)}

sumber energi terbarukan yang lebih optimal dengan menggunakan metode (MPPT) berbasis algoritme cerdas $(\mathrm{P} \& \mathrm{O})$ yang diterapkan di area kampus.

\section{A. Photovoltaic (PV)}

\section{TINJAUAN PUSTAKA}

Negara Indonesia yang berada di garis khatulistiwa mejadikannya memiliki potensi energi matahari yang cukup tinggi, karena matahari di Indonesia akan terus bersinar sepanjang tahun dengan rata-rata waktu sinar enam jam hingga delapan jam dalam satu hari. Sedangkan rata-rata penyinaran ideal yang dapat digunakanuntuk produksi listrik dengan PV adalah empat hingga lima jam [9]. Energi matahari merupakan radiasi elektromagnetik yang diproduksi oleh reaksi fusi nuklir pada pusat matahari. Energi cahaya matahari sampai ke bumi berbentuk paket-paket energi yang disebut dengan foton. Photovoltaik merupakan teknologi yang mengkonversi foton dari cahaya matahari menjadi energi listrik bebas polusi dan kebisingan [10].

Photovoltaik (PV) merupakan peralatan semikonduktor padat yang dapat mengkonversi radiasi matahari menjadi energi listrik dengan adanya efek Photovoltaik [11]. PV dapat Menghasilkan listrik searah (DC) diukur dalam watt $(\mathrm{W})$ atau kilowatt $(\mathrm{kW})$ [12]. Kinerja dari sel fotovoltaik bergantung pada ketersediaan cahaya matahari. Selama ada cahaya matahari, sel fotovoltaik akan menghasilkan energi listrik. Namun jika tidak ada cahaya matahari, tidak akan energi listrik yang dihasilkan. Sel fotovoltaik tidak membutuhkan pengisian energi selayaknya baterai (Erge et al.) Efek fotovoltaik terjadi ketika foton cahaya matahari menumbuk sel surya yang terbuat dari bahan semikonduktor, energi tumbukan tersebut ditransfer ke elektron. Energi yang diperoleh elektron menyebabkan elektron mengalir menjadi arus listrik [14].

\section{B. MPPT Algoritme Perturb and Observe $(P \& O)$}

PV merupakan peralatan semikonduktor padat yang dapat mengkonversi radiasi matahari menjadi energi listrik, namun besarnya daya output PV juga bergantung dengan temperature pada permukaan. Radiasi matahari dan suhu lingkungan yang tidak linear akan menyebabkan output daya pada PV menjadi naik turun dan tidak maksimal. MPPT Memungkinkan untuk melacak titik daya keluaran sistem PV yang paling maksimal dengan mengubah titik kerja sehingga converter akan memaksakan kerja panel surya sesuai kemampuan untuk selalu mencapai titik daya maksimum. Namun pengontrolan MPPT tidak akan berjalan dengan maksimal tanpa adanya sistem cerdas yang mampu menangani kasus pengoptimalan dalam sistem MPPT. Algoritme P\&O merupkan salah satu algoritme yang paling umum yang mudah di implementasikan dalam berbagai variasi daya [15]. $\mathrm{P} \& \mathrm{O}$ beroperasi dengan mengganggu secara berkala (yaitu menaikkan atau menurunkan) tegangan terminal array atau saat ini dan membandingkan daya keluaran PV dengan yang ada pada siklus gangguan sebelumnya. Algoritme $\mathrm{P} \& \mathrm{O}$ memungkinkan kinerja
MPPT yang lebih baik dan mampu menangani variasi daya dan tegangan pada PV sistem [1].

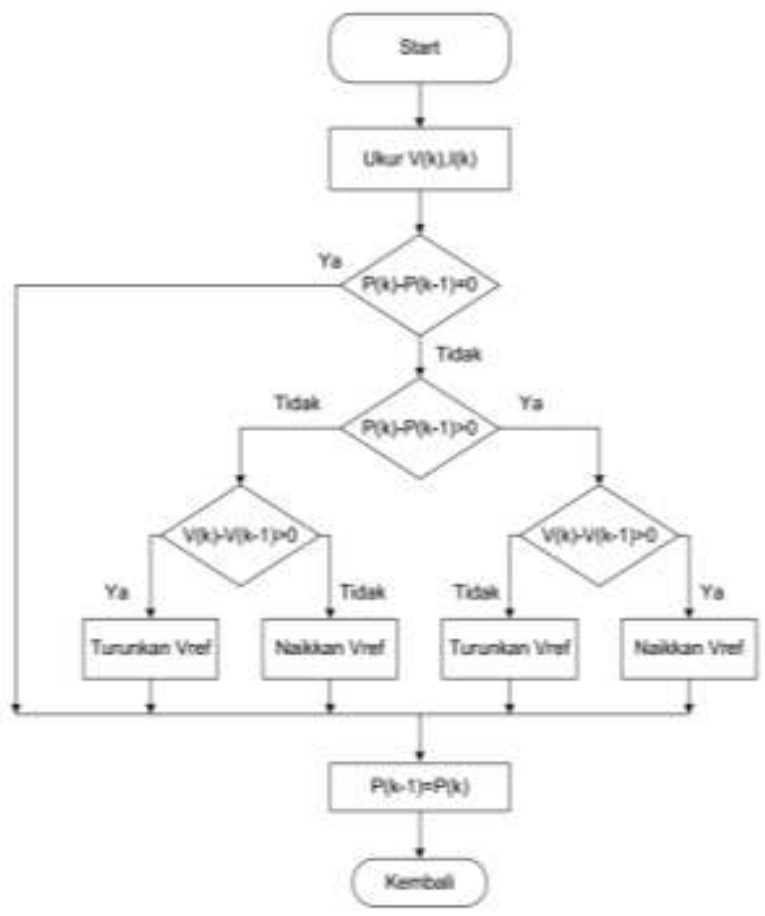

Gambar 1. Flowcart Algoritme P\&O

III. PROFIL STUDI LOKASI

Lokasi studi kasus penelitian adalah Teknik Elektro Fakultas Teknik Universitas Negeri Semarang (FT UNNES). FT UNNES terletak di Sekaran, Gunungpati, Kota Semarang dan memiliki iklim tropis dengan kordinat 7,05 LS, 110,40 BT, dan elevasi 187 mdpl [16] yang terlihat pada Gambar 2.

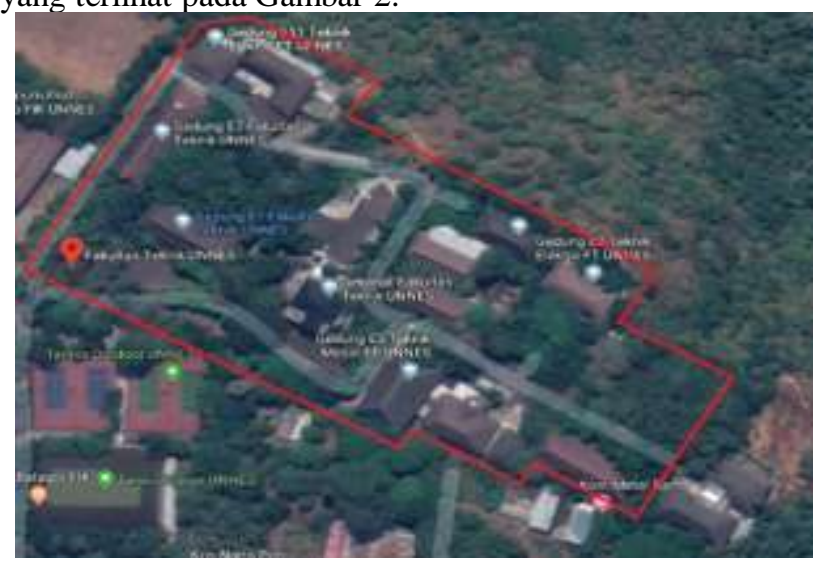

Gambar 2. Lokasi FT UNNES [16]

Aspek penting dalam merancang pembangkit fotovoltaik adalah data meteorologi tempat studi lokasi. Sumber energi matahari di lokasi mempengaruhi hasil produksi listrik. Akurasi data radiasi matahari, suhu lingkungan dan kecepatan angin sangat diperlukan [17]. Data meteorologi berupa profil iradiasi matahari dan suhu rata-rata di FT UNNES pada Gambar 3. 


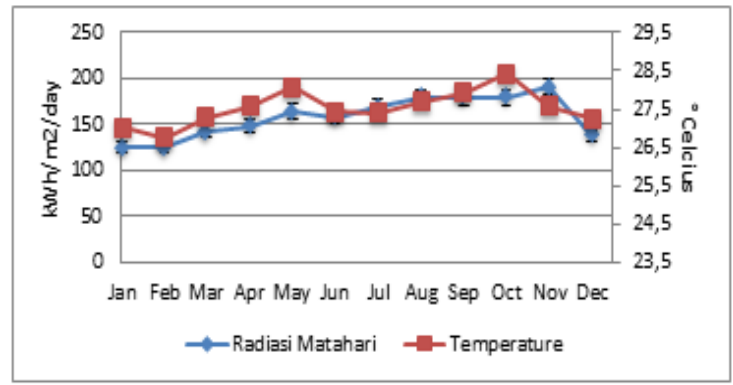

Gambar 3. Profil Iradiasi Matahari dan Suhu di FT UNNES [9]

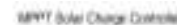

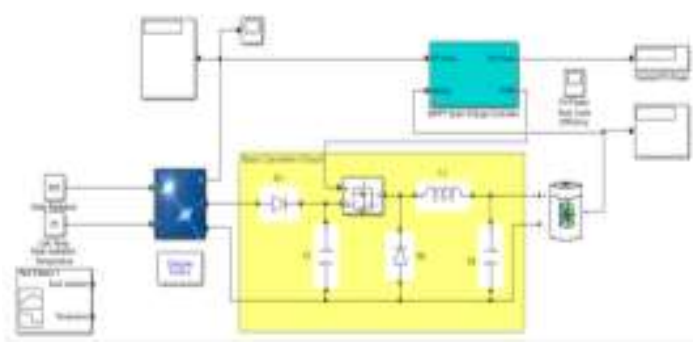

Gambar 4. Desain Sistem MPPT

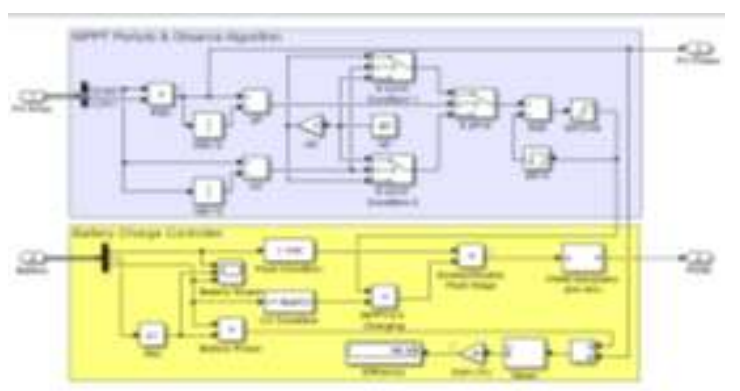

Gambar 5. Desain Algoritme P\&O dan Battery Conntroler

\section{HASIL DAN PEMBAHASAN}

Penelitian ini dilaksanakan dengan menggunakan bantuan Simulink MATLAB. Penyuplai energi utama dalam penelitian ini adalah sistem PV yang bekerja dengan memperhatikan suhu dan iradiasi matahari di lokasi penelitian. Sistem PV yang dirancang terdiri dari 6 buah modul PV yang disusun paralel 2 buah dan 4 PV disusun seri. Pengujian sistem PV dilakukan pada kondisi maksimal, yaitu pada kondisi radiasi 1000 $\mathrm{W} / \mathrm{m}^{2}$ dan temperature $25^{\circ} \mathrm{C}$.

Tegangan maksimal yang dapat dihasilkan oleh 6 modul $\mathrm{Pv}$ yang disusun Seri-Paralel mampu menghasilkan 123,166 Volts seperti yang terdapat pada gambar 6 yang dimulai pada waktu ke 1000 detik pertama.

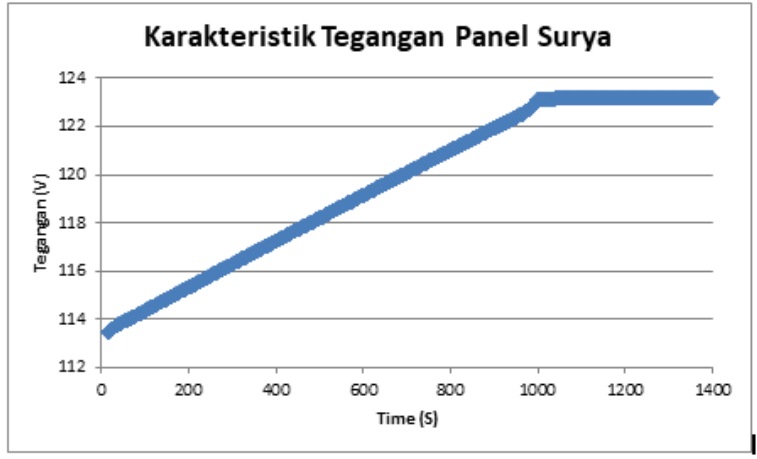

Gambar 6. Output Tegangan Sistem PV

Sedangkan Daya yang mampu dihasilkan oleh sistem yang dibangun adalah sebesar 1626,087 Watt seperti yang terlihat pada gambar 7 di detik ke 30 dan seterusnya.

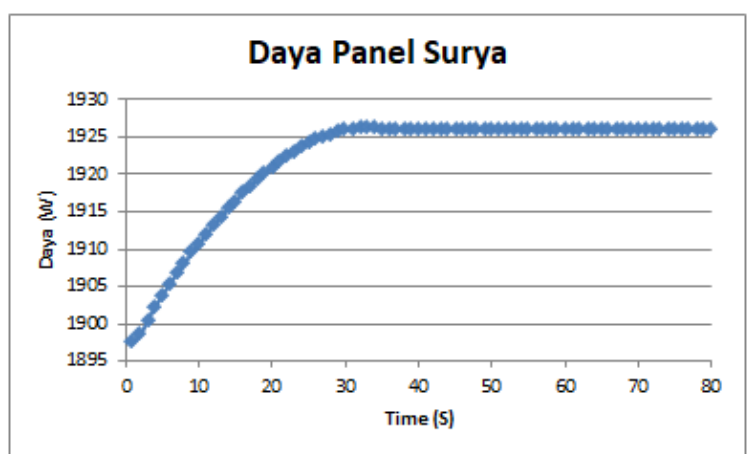

Gambar 7. Output Daya Sistem PV

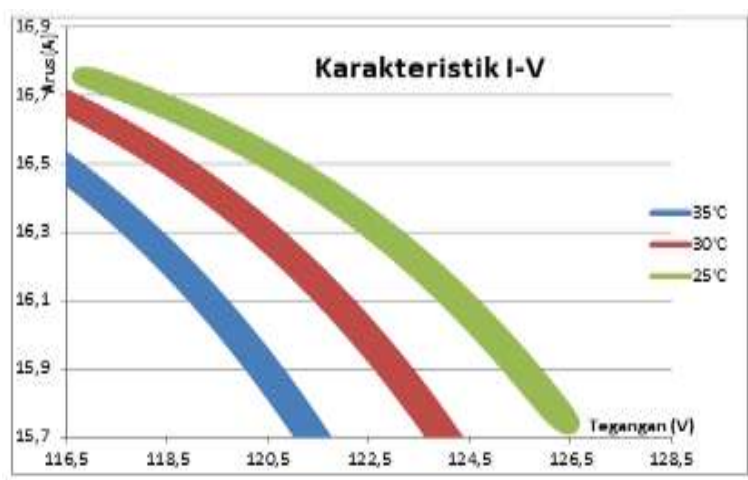

Gambar 8. Kurva Karakteristik I-V Dengan Variabel Temperature

Pengujian sistem PV juga dilakukan untuk melihat respon I-V pada sistem PV terhadap perubahan temperature yang dilakukan pada kondisi radiasi 1000 $\mathrm{W} / \mathrm{m}^{2}$ dengan variasi temperatue 25,30 , dan $35^{\circ} \mathrm{C}$, seperti yang terlihat pada gambar 8 . 


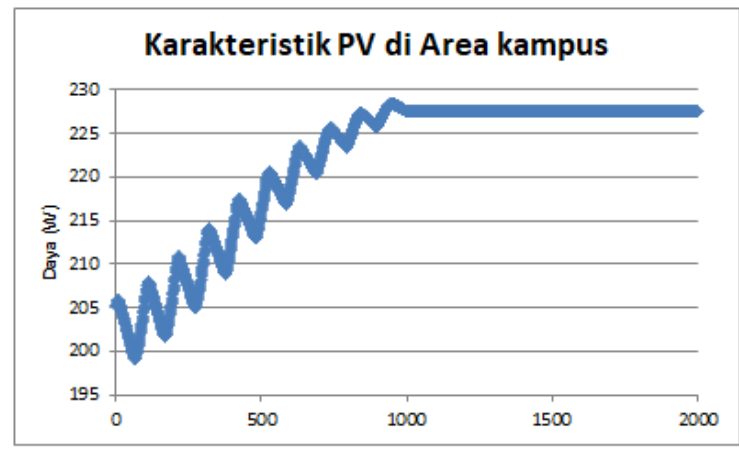

Gambar 9. Output Daya Sistem PV di Area Kampus

Serta dilakukan pengujian sistem PV pada kondisi radiasi dan temperature pada studi lokasi yaitu FT UNNES. Didapatkan daya maksimal sistem PV sebesar 227,585 Watt, seperti yang terlihat pada gambar 9.

\section{KESIMPULAN}

Berdasarkan hasil penelitian analisis sistem kendali Maximum Power Point Tracker (MPPT) berbasis Algoritme Perturb and Observe $(\mathrm{P} \& \mathrm{O})$ untuk sistem Photovoltaic (PV) standalone di area kampus, dapat disimpulkan bahwa sistem Optimasi PV dengan MPPT P\&O mampu menghasilkan daya yang stabil dan cukup besar pada kondisi iradiasi dan temperature optimal konvensional. MPPT berbasis Algoritme $\mathrm{P} \& \mathrm{O}$ juga mampu mengatasi kasus multi variabel pada saat diterapkan pada data real radiasi dan temperature di studi lokasi. Namun penggunaan algoritme $\mathrm{P} \& \mathrm{O}$ masih memerlukan waktu yang cukup lama pada saat PV pertama di operasikan untuk menvapai kondisi optimal yang stabil.

\section{DATAR PUSTAKA}

[1] J. Surya Kumari and C. Sai Babu, "Design and investigation of improved perturb \& observe MPPT algorithm for photovoltaic systems," $J$. Electr. Eng., vol. 14, no. 2, pp. 296-303, 2014.

[2] IRENA, "Renewable Energy Market Analysis: Southeast Asia," IRENA, pp. 1-168, 2018.

[3] ESDM, “Indonesia Energy Out Look 2019," J. Chem. Inf. Model., vol. 53, no. 9, pp. 16891699, 2019, doi: 10.1017/CBO9781107415324.004.

[4] A. J. Veldhuis and A. H. M. E. Reinders, "Reviewing the potential and costeffectiveness of grid-connected solar PV in Indonesia on a provincial level," Renew. Sustain. Energy Rev., vol. 27, pp. 315-324, 2013, doi: 10.1016/j.rser.2013.06.010.

[5] Syarif, Irwan, and Andi Nur Putri. "Konfigurasi Optimal Pembangkitan Hybrid Pembangkit Listrik Tenaga Surya Fotovoltaik Dan Diesel Berbasis Algoritma Genetika." Patria Artha Technological Journal 2.2 (2018): 101-108.

[6] Muhammad Ihsan Fadriantam, "Analisis
Perbandingan Kinerja Algoritme Perturb And Observe (P\&O) Dan Incremental Conductance (IC) Pada Sistem Kendali Maximum Power Point Tracker (MPPT) Untuk Sistem Photovoltaic (PV) Paralel," J. Chem. Inf. Model., vol. 53, no. 9, pp. 1689-1699, 2013.

[7] R. H. G. Tan, C. K. Er, and S. G. Solanki, "Modeling of Photovoltaic MPPT Lead Acid Battery Charge Controller for Standalone System Applications," E3S Web Conf., vol. 182, pp. 1-7, 2020, doi: 10.1051/e3sconf/202018203005.

[8] R. T. Widodo, P. Sejati, Asmuniv, and Rugianto, "Maximum Power Point Tracker Sel Surya Menggunakan Algoritma Perturb and Observe," Ind. Electron. Semin., no. 1, 2009.

[9] M. A. Hapsari, "Desain Dan Penilaian Building Attach Photovoltaic System Berbasis Fuzzy-Ahp Sebagai ( Studi Kasus : GedungGedung Teknik Elektro Unnes ) Photovoltaic System Berbasis Fuzzy-Ahp," 2019.

[10] I. Amin, N. Harun, and A. Suyuti, "Indonesia Berbasis Analisis RETScreen International: The Study of Renewable Energy Potential in Eastern," 2016.

[11] K. G. Jayanth and B. Venkatesh, "Performance Analysis of Solar Module with Climatic Data,” pp. 3468-3476, 2017, doi: 10.15662/IJAREEIE.2017.0605049.

[12] D. Erdogan, "Research on Building Integrated Photovoltaic Systems and Their Performance Evaluation," 2009.

[13] T. Erge, W. Weiß, F. I. N. Porvoo, and J. Royer, PHOTOVOLTAIC IN BUILDINGS: A Design Handbook for Architects and Engineers, 16th ed. Germany: XYZ Publishing Company.

[14] Usman, U., and Mochammad Apriyadi Hadi Sirad. "Characteristic Testing Of SimulationBased Photovoltaic Models." In IOP Conference Series: Materials Science and Engineering, vol. 1125, no. 1, p. 012064. IOP Publishing, 2021..

[15] Syarif, Irwan, and Andi Nur Putri. "Desain Simulasi Stabilitas Frekuensi Beban Hybrid PLTS Dengan PLTD." PROtek: Jurnal Ilmiah Teknik Elektro 7.1 : 45-50. 2020.

[16] Google Maps, "Fakultas Teknik Universitas Negeri Semarang," 2020.

[17] M. Klever, "Design and simulation of a gridconnected PV system in South Africa: technical, commercial and economical aspects," Master Thesis, 2018.

Copyright @2016 PROtek : Jurnal Ilmiah Teknik Elektro cc) (†) (ㄱ) lisensi Creative Commons Attribution 4.0 cc) In SA International Licensi 